\title{
THE DETECTION OF STREPTOMYCIN RESISTANCE IN TUBERCLE BACILLI
}

\author{
BY \\ SHEILA M. STEWART* \\ From the Department of Tuberculosis and Diseases of the Respiratory System, University of Edinburgh
}

(RECEIVED FOR PUBliCATION JANUARY 3, 1955)

It has been shown (Dye, Lynch, and Brees, 1953 ; Medical Research Council, 1953a and b ; Pitts, Tempel, Miller, Sands, Fitzpatrick, and Weiser, 1953) that the treatment of tuberculosis with two drugs simultaneously markedly reduces the incidence of bacterial resistance provided that the organisms are fully sensitive to both drugs. If, however, the organisms are resistant to one of the drugs, resistance will develop to the second as quickly as if that drug were being given alone (Turnbull, Wallace, Stewart, and Crofton, 1953). Evidence obtained in this unit (to be published elsewhere) suggests that it is important to use a routine sensitivity test which will detect even low degrees of resistance. In Great Britain the generally accepted routine test for detecting streptomycin resistance in tubercle bacilli is that of serial dilution in Dubos and Davis liquid medium as recommended by the Medical Research Council (1953c). But in this unit we have had a number of patients excreting organisms which appeared to be sensitive by the routine test, although other factors in the cases suggested that streptomycinresistant bacilli had emerged. In the present report an alternative method is described for the detection of streptomycin resistance in Myco. tuberculosis which appears to be more sensitive than the previous routine test.

\section{Material}

All strains of Myco. tuberculosis used were obtained from the sputa of patients with pulmonary tuberculosis. The sputa were homogenized by the alkaliacid or tri-basic sodium phosphate method, and cultured on Löwenstein-Jensen medium. The time between the inoculation of the culture and the testing for streptomycin resistance varied from four weeks to five months.

The cultures used are grouped as follows :

(1) Twenty-nine cultures from 29 patients who had never received streptomycin, to show the normal variation of the method.

\footnotetext{
* Royal Victoria Hospital Tubsrculosis Trust Research Fellow in Bacteriology.
}

(2) Thirty-four cultures which on the routine test appeared to be sensitive to streptomycin although they came from 22 patients whose organisms were suspected of being resistant for one or more of the following reasons : (a) Streptomycin was known to have been given previously alone or in combination with other drugs to which the patients' organisms were known to be resistant. (b) Isoniazid (isonicotinic acid hydrazide) resistance had developed during combined treatment with streptomycin and isoniazid. All of these patients had previously received streptomycin alone or in combination with $p$-aminosalicylic acid (P.A.S.), when their organisms had already become resistant to P.A.S. (c) The occurrence of apparent sensitivity to streptomycin in spite of the fact that on previous occasions resistance to the drug had been found by the routine test.

(3) Fifteen cultures from 15 patients from whom previous cultures had been shown to be resistant to streptomycin by the routine test to determine whether any of these cultures might appear sensitive by the new test.

\section{Methods}

The streptomycin sensitivity of the cultures was tested by the routine liquid medium method and by a solid medium method simultaneously. In both cases the standard $\mathrm{H} 37 \mathrm{Rv}$ strain of Myco. tuberculosis was used as the control organism. The results were reported as a resistance ratio, that is the ratio of the minimum inhibitory concentration for the test organism to the minimum inhibitory concentration for the control strain.

Routine Liquid Medium Test.-The routine method was that recommended by the Medical Research Council (1953c) using Dubos and Davis' " Tween 80 "albumin medium (Dubos and Davis, 1946). The drug concentrations used were $8,4,2,1,0.5,0.25$, and $0.125 \mu \mathrm{g}$. per $\mathrm{ml}$. of medium. The tubes were inoculated from a second subculture of the organisms in Dubos and Davis medium. All tests were read after 10 days' incubation and some were also read after 28 days.

Solid Medium Test.-The organisms were tested for resistance to streptomycin on Löwenstein-Jensen medium at concentrations of $64,32,16,8,4,2,1$, and 0.5 $\mathrm{kg} . / \mathrm{ml}$. These concentrations represent the actual 
amount of streptomycin added to the medium. After the addition of the streptomycin approximately $2 \mathrm{ml}$. quantities were dispensed into $\frac{1}{4} \mathrm{oz}$. screw-capped bottles. These were inspissated in the horizontal position for one hour at 75 to $80^{\circ} \mathrm{C}$. A suspension of a loopful of the growth of the primary culture of the organism was made in $0.3 \mathrm{ml}$. sterile distilled water by shaking with glass beads in a mechanical shaker. Using a nichrome wire loop of $3 \mathrm{~mm}$. diameter, a loopful of the suspension was streaked up the centre of the slope. The slopes were incubated at $37^{\circ} \mathrm{C}$. Readings were made at three, four, five, and six weeks. Growth was considered to be inhibited by the drug if fewer than 20 colonies appeared on the slope.

Solid Medium Test from the Liquid Medium Culture.-In order to ascertain whether resistance detected by the solid medium test but not by the liquid medium method was due to a failure of the resistant organisms to grow in the liquid medium subculture used for the routine test, a series of tests on solid medium was carried out using a loopful of the liquid medium subculture instead of the suspension. The number of organisms present in these two inocula is approximately the same.

Liquid Medium Tests without "Tween 80."-In order to ascertain whether the failure to detect resistance was due to the presence in the routine medium of "Tween 80,' a series of tests was carried out in medium which did not contain any of this substance. The method used for these tests was exactly the same as for the routine test in all other respects. The liquid medium subculture from which the tests were inoculated contained "Tween 80."

\section{Results}

Cultures from Patients Who Had Never Received Streptomycin.-Table I shows the three and four weeks' readings of the solid medium tests on the 29 pre-treatment cultures. The results are expressed as resistance ratios. It will be seen that

TABLE I

NORMAL DISTRIBUTION OF RESISTANCE RATIOS ON SOLID MEDIUM TEST AFTER THREE AND FOUR WEEKS INCUBATION

\begin{tabular}{|c|c|c|c|c|c|c|c|}
\hline \multirow{2}{*}{$\begin{array}{c}\text { Incubation } \\
\text { Period }\end{array}$} & \multicolumn{6}{|c|}{$\begin{array}{l}\text { No. of Cultures Showing } \\
\text { Resistance Ratio }\end{array}$} & \multirow{2}{*}{ Tota } \\
\hline & $\frac{1}{8}$ & $\frac{1}{4}$ & $\frac{1}{2}$ & 1 & 2 & 4 & \\
\hline $\begin{array}{ll}3 \text { weeks } & . \\
4 & \end{array}$ & $\begin{array}{l}3 \\
0\end{array}$ & $\begin{array}{l}4 \\
4\end{array}$ & $\begin{array}{r}9 \\
11\end{array}$ & $\begin{array}{l}9 \\
8\end{array}$ & $\begin{array}{l}3 \\
5\end{array}$ & $\begin{array}{l}1 \\
1\end{array}$ & $\begin{array}{l}29 \\
29\end{array}$ \\
\hline
\end{tabular}

at three weeks the readings fell within the range $\frac{1}{8}$ to 4 . At four weeks this range was narrowed to $\frac{1}{4}$ to 4 . Results at five and six weeks were similar to those found on the four weeks' reading. The range of inhibition for the test organisms varied from 1 to $16 \mu \mathrm{g}$. $/ \mathrm{ml}$. and for the standard H37Rv strain from 4 to $8 \mu \mathrm{g}$. $/ \mathrm{ml}$.
From the normal distributions the standard $\%$ deviation of the three weeks' readings is 1.217 and $\vec{F}$ of the four weeks' readings is 1.013 . The limiting resistance ratio for $\mathrm{P}=0.01$ is 8 for the three weeks' results and 4 at four weeks. In view of $\overline{\bar{\omega}}$. these results it was considered that a four-week $\vec{\nabla}$ reading would be the most satisfactory to use.

The 29 pre-treatment cultures were also tested by the liquid medium method. The results of $\overrightarrow{0}$ both methods, expressed as resistance ratios, are $\overrightarrow{-}$ compared in Table II. By each method 28 of the $\mathcal{O}^{-}$ 29 cultures tested gave a resistance ratio of 2 or less. By each method one strain gave a resistance

TABLE II

COMPARISON OF RESULTS OF LIQUID AND SOLID MEDIA W TESTS ON 29 CULTURES FROM 29 PATIENTS WHOO HAD NEVER RECEIVED STREPTOMYCIN

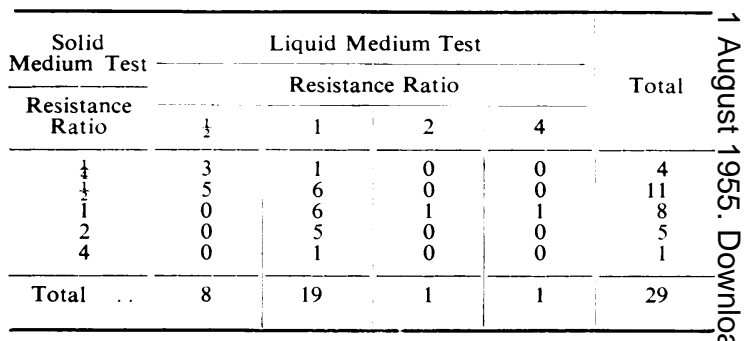

"Resistance ratio" = the ratio of the minimum inhibitory concentration for the test organism to the minimum inhibitory concen- $\mathbb{D}$ tration for the standard H37Rv strain.

The standard strain was inhibited by concentrations varying from 0.25 to $0.5 \mu \mathrm{g} \mathrm{ml}$. in the liquid medium and from 4 to $8 \mu \mathrm{g}$. ml. in the solid medium.

The liquid medium tests were read at 10 days and the solid medium tests at four weeks.

ratio of 4 . Both the patients from whom these latter two strains were isolated have subsequently? been treated with streptomycin in combination $\frac{}{3}$ with another drug. In neither case has their subsequent progress suggested that the organismso were resistant to streptomycin.

By the routine liquid medium test the minimum? inhibitory concentration for the test organisms varied from 0.125 to $1.0 \mu \mathrm{g}$. $/ \mathrm{ml}$. and that of the standard $\mathrm{H} 37 \mathrm{Rv}$ strain from 0.25 to $0.5 \mu \mathrm{g} . / \mathrm{ml}$. N From the normal distributions of the 29 cultures also tested by the solid medium method, the standard deviation is 0.591 and the limiting resis- $\omega$ tance ratio for $\mathbf{P}=0.01$ is just over 2 . Utilizing a further 41 cultures tested by the liquid methodo only, the limiting resistance ratio is again just overष्ठ 2. Since the tests are carried out with twofold? differences between the concentrations, this means $-{ }^{\circ}$ that the lowest resistance ratio giving a 99 to $1 \stackrel{\text { 吕 }}{\circ}$ probability of resistance is 4 .

Although the numbers in these series are rather $\stackrel{\mathbb{Q}}{2}$ small for statistical analysis, the results suggesto that by either method a resistance ratio of 4 willo 
only be obtained with one pre-treatment culture in 100 . Therefore a ratio of 4 by either method has been taken as indicative of the emergence of a resistant strain.

Cultures Appearing Sensitive by Routine Test although Suspected of Resistance.-Table III gives the results of the solid medium test on 34 cultures which were sensitive on the routine liquid medium test. In every patient from whom these cultures were obtained streptomycin resistance was suspected for the reasons shown. It will be seen that in only one culture was a sensitive result found on the solid medium test. Of the remaining 33 cultures, 10 gave a resistance ratio of 4 , nine of 8 , seven of 16 , and seven of greater than 16 .

TABLE III

RESULTS OF SOLID MEDIUM TESTS ON 34 CULTURES FROM 22 PATIENTS WITH SUSPECTED STREPTOMYCIN
RESISTANCE ALTHOUGH SENSITIVE BY ROUTINE TEST

\begin{tabular}{|c|c|c|c|c|c|c|c|c|}
\hline \multirow{3}{*}{$\begin{array}{l}\text { Reason for } \\
\text { Suspecting } \\
\text { Streptomycin } \\
\text { Resistance }\end{array}$} & \multirow{3}{*}{$\begin{array}{c}\text { No. } \\
\text { of } \\
\text { Patients }\end{array}$} & \multirow{3}{*}{$\begin{array}{c}\text { No. } \\
\text { of } \\
\text { Cultures }\end{array}$} & \multicolumn{6}{|c|}{ Solid Medium Test } \\
\hline & & & \multicolumn{6}{|c|}{ Resistance Ratio } \\
\hline & & & 1 & 2 & 4 & 8 & 16 & $>16$ \\
\hline \multirow{3}{*}{$\begin{array}{l}\text { Previous unsatis- } \\
\text { factory chemo- } \\
\text { therapy } \\
\text { Later resistance to } \\
\text { second drug . } \\
\text { Resistance previ- } \\
\text { ously shown by } \\
\text { liquid medium } \\
\text { test } . . \quad \ldots\end{array}$} & 9 & 13 & 0 & 0 & 5 & 1 & 5 & 2 \\
\hline & 3 & 5 & 1 & 0 & 2 & 1 & 0 & 1 \\
\hline & 10 & 16 & 0 & $\mathbf{0}$ & 3 & 7 & 2 & 4 \\
\hline Totals & 22 & 34 & 1 & 0 & 10 & 9 & 7 & 7 \\
\hline
\end{tabular}

Cultures Resistant by the Routine Test.-A comparison of the degree of streptomycin resistance found by the liquid and solid medium tests on cultures resistant by both methods is shown in Table IV. It will be seen that all the cultures showing resistance by the routine test also showed resistance when tested on the solid medium.

TABLE IV

COMPARISON OF DEGREE OF RESISTANCE BY LIQUID AND SOLID MEDIUM TESTS ON 15 CULTURES OF KNOWN

\begin{tabular}{c|c|c|c|c|c}
\multicolumn{2}{c|}{ RESISTANCE BY LIQUID MEDIUM TEST } \\
\hline $\begin{array}{c}\text { Resistance } \\
\begin{array}{c}\text { Ratio in } \\
\text { Solid } \\
\text { Medium Test }\end{array}\end{array}$ & \multicolumn{4}{|c|}{$\begin{array}{c}\text { Resistance Ratio in } \\
\text { Liquid Medium Test }\end{array}$} & Total \\
\cline { 2 - 5 } & 4 & 8 & 16 & $>16$ & \\
\hline 4 & 0 & 0 & 0 & 0 & 0 \\
8 & 2 & 0 & 0 & 0 & 2 \\
$>16$ & 0 & 0 & 0 & 0 & 0 \\
\hline 16 & 3 & 2 & 2 & 6 & 13 \\
\hline Total & 5 & 2 & 2 & 6 & 15 \\
\hline
\end{tabular}

Cultures from Patients not Expected to Yield Streptomycin-resistant Organisms. - Twenty-four cultures, from patients in whom there was no reason to suspect the emergence of resistance, were all found to be sensitive by both methods.

Effect of Prolonged Incubation on Results of Liquid Medium Tests.-Table V shows the results of the liquid medium test after 10 and 28 days' incubation on 19 cultures which were resistant on the solid medium. It will be seen that in no

TABLE V

RESULTS OF LIQUID MEDIUM TEST AFTER 10 AND 28 DAYS' INCUBATION ON 19 KNOWN RESISTANT CULTURES

\begin{tabular}{|c|c|c|c|c|c|c|c|c|c|}
\hline \multirow{3}{*}{$\begin{array}{c}28 \text { Days' } \\
\text { Reading } \\
\text { Resistance } \\
\text { Ratio }\end{array}$} & \multicolumn{8}{|c|}{10 Days' Reading Resistance Ratio } & \multirow{3}{*}{ Total } \\
\hline & \multicolumn{4}{|c|}{ Sensitive } & \multicolumn{4}{|c|}{ Resistant } & \\
\hline & t & $\frac{1}{2}$ & 1 & 2 & 4 & 8 & 16 & $>16$ & \\
\hline 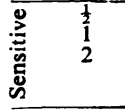 & $\begin{array}{l}1 \\
0 \\
0\end{array}$ & $\begin{array}{l}2 \\
1 \\
0\end{array}$ & $\begin{array}{l}1 \\
1 \\
0\end{array}$ & $\begin{array}{l}0 \\
3 \\
5\end{array}$ & $\begin{array}{l}0 \\
0 \\
0\end{array}$ & $\begin{array}{l}0 \\
0 \\
0\end{array}$ & $\begin{array}{l}\mathbf{0} \\
\mathbf{0} \\
\mathbf{0}\end{array}$ & $\begin{array}{l}\mathbf{0} \\
\mathbf{0} \\
\mathbf{0}\end{array}$ & $\begin{array}{l}4 \\
5 \\
5\end{array}$ \\
\hline 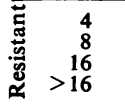 & $\begin{array}{l}\mathbf{0} \\
0 \\
0 \\
0\end{array}$ & $\begin{array}{l}0 \\
0 \\
0 \\
0\end{array}$ & $\begin{array}{l}0 \\
0 \\
0 \\
0\end{array}$ & $\begin{array}{l}0 \\
0 \\
0 \\
0\end{array}$ & $\begin{array}{l}0 \\
1 \\
0 \\
0\end{array}$ & $\begin{array}{l}0 \\
0 \\
0 \\
0\end{array}$ & $\begin{array}{l}\mathbf{0} \\
\mathbf{0} \\
0 \\
\mathbf{0}\end{array}$ & $\begin{array}{l}0 \\
0 \\
0 \\
4\end{array}$ & $\begin{array}{l}0 \\
1 \\
0 \\
4\end{array}$ \\
\hline Total & 1 & 3 & 2 & 8 & 1 & 0 & 0 & 4 & 19 \\
\hline
\end{tabular}

case was the resistance ratio at 28 days more than twice that found at 10 days. No culture that gave a sensitive reading at 10 days appeared to be resistant at 28 days.

Effect of "Tween 80 " on Results of Liquid Medium Tests.-A comparison of the liquid medium tests carried out with and without "Tween 80 " on 27 cultures that were resistant to streptomycin on the solid medium is shown in Table VI.

TABLE VI

RESULTS OF TESTS IN LIQUID MEDIUM WITH AND WITHOUT "TWEEN 80 " ON 27 KNOWN RESISTANT CULTURES BY SOLID MEDIUM TEST

\begin{tabular}{|c|c|c|c|c|c|c|c|c|}
\hline \multirow{3}{*}{\multicolumn{2}{|c|}{$\begin{array}{c}\text { Resistance } \\
\text { Ratio in } \\
\text { Liquid Medium } \\
\text { Without } \\
\text { " Tween 80" }\end{array}$}} & \multicolumn{6}{|c|}{$\begin{array}{l}\text { Resistance Ratio in } \\
\text { Liquid Medium with " Tween } 80 \text { " }\end{array}$} & \multirow{3}{*}{ Total } \\
\hline & & \multicolumn{2}{|c|}{ Sensitive } & \multicolumn{4}{|c|}{ Resistant } & \\
\hline & & 1 & 2 & 4 & 8 & 16 & $>16$ & \\
\hline 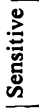 & $\begin{array}{l}1 \\
2\end{array}$ & $\begin{array}{l}0 \\
2\end{array}$ & $\begin{array}{l}\mathbf{0} \\
\mathbf{0}\end{array}$ & $\begin{array}{l}\mathbf{0} \\
\mathbf{0}\end{array}$ & $\begin{array}{l}\mathbf{0} \\
\mathbf{0}\end{array}$ & $\begin{array}{l}0 \\
0\end{array}$ & $\begin{array}{l}0 \\
0\end{array}$ & $\begin{array}{l}\mathbf{0} \\
\mathbf{2}\end{array}$ \\
\hline \multirow[t]{2}{*}{ 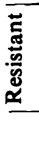 } & $\begin{array}{r}4 \\
8 \\
16 \\
>16\end{array}$ & $\begin{array}{l}2 \\
1 \\
0 \\
0\end{array}$ & $\begin{array}{l}7 \\
1 \\
1 \\
1\end{array}$ & $\begin{array}{l}1 \\
2 \\
0 \\
3\end{array}$ & $\begin{array}{l}0 \\
0 \\
0 \\
1\end{array}$ & $\begin{array}{l}0 \\
0 \\
0 \\
1\end{array}$ & $\begin{array}{l}0 \\
0 \\
0 \\
4\end{array}$ & $\begin{array}{r}10 \\
4 \\
1 \\
10\end{array}$ \\
\hline & Total $\ldots$ & 5 & 10 & 6 & 1 & 1 & 4 & 27 \\
\hline
\end{tabular}

Assuming that a resistance ratio of 4 indicates resistance by either method, it will be seen that of the 27 cultures tested two appeared to be sensitive when "Tween 80 " was absent from the medium and 15 when "Tween 80 " was present. 
Comparison of Results of Solid Medium Test Inoculated from a Suspension of Primary Culture or Liquid Medium Subculture.-Table VII gives a comparison of the degrees of resistance found on solid medium tests inoculated from a suspension of the primary culture or from the subculture in the liquid medium. It will be seen that 37 of the 38 cultures were resistant by both methods. From only one culture was a sensitive result obtained from the liquid medium subculture, where a resistant result was found on the direct test.

TABLE VII

RESULTS OF SOLID MEDIUM TESTS ON 38 CULTURES ON A SUSPENSION OF PRIMARY CULTURE AND LIQUID MEDIUM SUBCULTURE

\begin{tabular}{|c|c|c|c|c|c|c|c|}
\hline \multirow{2}{*}{$\begin{array}{c}\text { Resistance } \\
\text { Ratio } \\
\text { in Direct } \\
\text { Test }\end{array}$} & \multicolumn{6}{|c|}{$\begin{array}{c}\text { Resistance Ratio in } \\
\text { Test from Liquid Medium Subculture }\end{array}$} & \multirow{2}{*}{ Total } \\
\hline & 1 & 2 & 4 & 8 & 16 & $>16$ & \\
\hline $\begin{array}{r}4 \\
8 \\
16 \\
>16\end{array}$ & $\begin{array}{l}1 \\
0 \\
0 \\
0\end{array}$ & $\begin{array}{l}0 \\
0 \\
0 \\
0\end{array}$ & $\begin{array}{l}2 \\
3 \\
2 \\
0\end{array}$ & $\begin{array}{l}3 \\
2 \\
2 \\
1\end{array}$ & $\begin{array}{l}1 \\
2 \\
2 \\
3\end{array}$ & $\begin{array}{r}1 \\
1 \\
0 \\
12\end{array}$ & $\begin{array}{r}8 \\
8 \\
6 \\
16\end{array}$ \\
\hline Total . . & 1 & 0 & 7 & 8 & 8 & 14 & 38 \\
\hline
\end{tabular}

Incidence of Resistance to P.A.S. and Isoniazid. -Of the 33 strains resistant to streptomycin on the solid medium test but not by the liquid medium method, 25 were resistant to P.A.S. and 22 to isoniazid.

\section{Discussion}

It is now well known that to use streptomycin in combination with isoniazid or P.A.S. in the treatment of tuberculosis only reduces the incidence of bacterial resistance to the second drug if the organisms are fully sensitive to streptomycin. It was therefore a little disturbing to find that in a number of cases the organisms appeared sensitive by the accepted routine liquid medium test, although other factors suggested that the organisms had developed streptomycin resistance. The value of streptomycin therapy in these cases was doubtful. A solid medium test was therefore tried in order to determine whether or not these cultures were in fact resistant to streptomycin. The results of these investigations are reported in this communication.

From the normal distribution curve of 29 cultures from patients who had never received streptomycin, it appears that in only one case in a hundred would a resistance ratio of 4 be found by the solid medium method. It therefore seems reasonable that for clinical practice a reading of 4 or above should be taken as indicating the development of resistance.

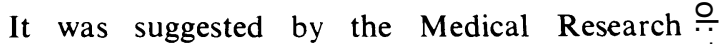
Council (1953c) that by the liquid medium test $\underset{\vec{O}}{\vec{\rho}}$ a resistance ratio of 8 was the lowest indicating $\frac{7}{0}$ resistance. The results of the present series suggest $\frac{5}{5}$ that a ratio of 4 is indicative of resistance $99 \frac{\bar{\omega}}{\mathrm{N}}$ times out of 100 . In fact the limiting resistance $\frac{\mathbb{}}{\mathbb{}}$ ratio is only just above 2 and if a narrower $\frac{\circ}{2}$ bracketing were used for the streptomycin con- $\delta$ centrations a lower level might be found to be $\overrightarrow{0}$ significant.

Tests on both solid and liquid medium were $\vec{\omega}$ made on 34 cultures from patients in whom the existence of resistant tubercle bacilli was suspected ${ }_{\infty}^{\circ}$ either because of previous unsatisfactory chemo- $\dot{\omega}$ therapy, or because of resistance having been known to have been present on a previous occa- $y$ sion, or because resistance developed to a second 옹 drug during treatment with that drug and strepto- $\rightarrow$ mycin in doses known to prevent the emergence of drug-resistant bacilli. All these cultures were sensitive by the liquid medium test. On solid $\stackrel{\oplus}{\rightarrow}$ medium 33 gave a reading of 4 or above, 23 of $\overrightarrow{0}$ those being 8 or over. On only one culture from a or case where there was reason to suspect the presence 0 of streptomycin resistance was a sensitive result obtained on solid medium. Therefore in cases where resistance was shown by the solid medium method there was other evidence that resistance $\frac{}{D}$

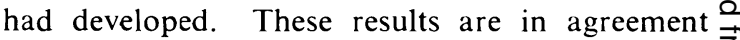
with those reported by Holt and Cruickshank (1949) although they inoculated the solid medium tubes direct from the sputum concentrate.

All of the 15 cultures which showed resistance by the liquid medium test also appeared resistant $\frac{0}{0}$ by the solid medium test. It would therefore $\overline{0}$ seem unlikely that by using the solid medium method a culture would be reported as sensitive $\delta$ which would have been resistant by the routine method.

The solid medium was not used as a screening $D$ method, and therefore there was less chance of detecting cultures resistant on the liquid medium $N$ but sensitive on the solid medium test. But of 24 cultures from patients in whom there was no reason to suspect the emergence of streptomycin $\omega$ resistance all were sensitive to the drug by both? methods.

The question arises as to why there is this difference in the results of the two methods. It ? has been suggested that the detection of resistance $\frac{T}{T}$ by the solid medium test is due to the longer $\frac{P}{\mathbb{D}}$ incubation period which allows of the appearance $\stackrel{\odot}{\oplus}$ of the organisms with a slower growth rate. Re- $\mathbb{Q}$ sults of the prolonged incubation of the liquid? medium test do not support this theory. Of the 190 
cultures tested, no culture giving a sensitive reading at 10 days appeared resistant after 28 days.

It has previously been found that the presence of "Tween 80 " in the liquid medium enhances the inhibitory activity of streptomycin. Fisher (1948a) showed that of 20 strains tested in two types of liquid medium, $25 \%$ were resistant in Dubos and Davis' medium containing "Tween 80 " whereas $55 \%$ were resistant when tested in Youmans medium where no "Tween" was used. This was also shown by testing strains for streptomycin sensitivity in a basal medium with the addition of "Tween 80 " and of albumin singly and together (Fisher, 1948b). It was suggested that the use of $0.3 \%$ albumin in the Dubos and Davis' medium was sufficient to inactivate the "Tween 80" (Medical Research Council, 1948). In the present series only two of the 27 cultures resistant on solid medium were sensitive in the absence of "Tween 80," while 15 were sensitive when "Tween" was present, in spite of the addition of $0.3 \%$ of bovine albumin to the medium. Further work on this is being carried out.

It was possible that the differences in the results obtained in the liquid and solid media were due to a failure of the resistant organisms to grow in the liquid medium subculture from which the routine tests were inoculated. But resistance was demonstrated in 37 out of 38 cases where solid medium tests were inoculated from these subcultures.

The main disadvantage in using the LöwensteinJensen medium is the alleged breakdown of the streptomycin during inspissation. This might result in sensitive strains appearing resistant if a fixed minimum inhibitory concentration is used as indication of resistance. But the problem is largely overcome if the results are expressed as resistance ratios.

Of the 33 strains resistant to streptomycin on the solid medium but sensitive when tested in liquid medium, 25 were resistant to P.A.S. and 22 to isoniazid. The differences between the results of the streptomycin sensitivity tests by the two methods do not therefore seem to be related to resistance to either of these drugs.

In conclusion, it would seem that the solid medium test described will detect streptomycin resistance in tubercle bacilli more readily than will the routine liquid medium test.

\section{Summary}

A method is described for testing the streptomycin sensitivity of tubercle bacilli in LöwensteinJensen medium. The results are compared with those obtained in Dubos and Davis' liquid medium.

It is concluded that a resistance ratio of 4 by either method indicates resistance. Using this criterion, 33 of the 34 cultures tested from patients whose organisms were suspected of being resistant, were resistant by the solid medium test, although none were resistant by the liquid medium test.

There was no evidence that the solid medium test failed to detect resistance in cultures resistant by the liquid medium test.

The differences in the results of the two methods were not accounted for by the prolonged incubation of the solid medium test nor by the failure of the resistant organisms to grow in the liquid medium subculture.

The failure to demonstrate streptomycin resistance in the liquid medium may be due to the presence of "Tween 80 ."

I would like to thank Professor J. W. Crofton for his help and advice in this work, Dr. F. W. A. Turnbull for his assistance in obtaining the clinical details of the cases and in drawing up the tables, and Drs. I. W. B. Grant, N. W. Horne, and J. D. Ross for allowing me to investigate their cases and for bringing many of the cases to my notice. Dr. A. T. Wallace carried out the original routine tests. I am grateful to Dr. D. A. Mitchison for helpful criticism. Mr. D. Hay gave valuable technical assistance. The work was supported by a generous grant from the Royal Victoria Hospital Tuberculosis Trust.

\section{REFERENCES}

Dubos, R. J., and Davis, B. D. (1946). J. exp. Med., 83, 409.

Dye, W. E., Lynch, Helen P., and Brees, Atlanta G. (1953). Amer. Rev. Tuberc., 67, 106.

Fisher, M. W. (1948a). Ibid., 57, 53.

- (1948b). Ibid., 57, 58.

Holt, H. D., and Cruickshank, R. (1949). Monthly Bull. Minist. Hlth, Lond., 8, 103.

Medical Research Council (1948). Lancet, 2, 862. - (1953a). Brit. med. J., 1, 521.

- (1953b). Ibid., 2, 1005.

(1953c). Lancet, 2, 213.

Pitts, F. W., Tempel, C. W., Miller, F. L., Sands, J. H., Fitzpatrick, M. J., and Weiser, O. (1953). J. Amer. med. Ass., 152, 886.

Turnbull, F. W. A., Wallace, A. T., Stewart, Sheila, and Crofton, J. W. (1953). Brit. med. J., 1. 1244. 